Cutting the mustard: new insights into the plant economy of Late Neolithic Tepe Khaleseh (Iran)

Jade Whitlam $^{1}$, Hamid Reza Valipour ${ }^{2}$ and Michael Charles ${ }^{1}$

${ }^{1}$ School of Archaeology, University of Oxford, Oxford, UK

${ }^{2}$ Department of Archaeology, Shahid Beheshti University, Tehran, Iran

Address: Institute of Archaeology, 34-36 Beaumont Street, Oxford, UK. OX2 6DL;

Email: jade.whitlam@arch.ox.ac.uk 


\title{
Cutting the mustard: new insights into the plant economy of Late Neolithic Tepe Khaleseh (Iran)
}

\begin{abstract}
Excavations at Tepe Khaleseh, a small-settlement mound in the Zanjan Province of northwest Iran, have uncovered numerous structures dating to the second half of the sixth millennium B.C., including a pottery kiln. The charred plant remains recovered from the site provide evidence for the cultivation of a diverse spectrum of cereals, along with pulses, which are rare at contemporary sites in the region. Analysis of the archaeobotanical assemblage has also permitted a reconstruction of fuel use at the site, with wild mustards identified as having played a key role in the settlement's fuel economy. The results presented here expand significantly on our understanding of plant management in northern Iran during the Late Neolithic, a period when we see the spread of farming out of the Fertile Crescent and into Eurasia.
\end{abstract}

Keywords: archaeobotany; Neolithic; spread of farming; fuel; wild mustards

\section{Introduction}

This paper presents the results of an archaeobotanical study undertaken at Late Neolithic Tepe Khaleseh in the Zanjan Province of northwest Iran. ${ }^{1}$ Northwest Iran is a key region for investigating the spread of agriculture out of southwest Asia, linking the eastern arm of the Fertile Crescent with Caucasia to the north and central Asia to the east. However, archaeobotanical data with which to reconstruct Late Neolithic farming economies in the region is scarce. While the spread of farming westwards into Europe can be traced through a series of well dated sites and archaeobotanical assemblages, ${ }^{2}$

\footnotetext{
${ }^{1}$ Valipour et al., 'Tepe Khaleseh, a Late Neolithic Site in Zanjan Province'; Valipour et al., 'Tepe Khaleseh: Archaeological Evaluation of a Late Neolithic Site in North-Western Iran'.

${ }^{2}$ Bogaard, Neolithic Farming in Central Europe: An Archaeobotanical Study of Crop Husbandry Practices; Zohary, Hopf, and Weiss, Domestication of Plants in the Old World.
} 
few records are available that document its eastward trajectory, particularly along the north Iranian corridor. Apart from Khaleseh, the only contemporary sites in northern Iran that have produced charred plant remains to date, are Chahar Boneh in the Qazvin plain ${ }^{3}$ and Sang-e Chakhmaq at the eastern edge of the Caspian Sea ${ }^{4}$ (Fig. 1). Along with Jeitun, which is located near to the Iranian border in Turkmenistan, ${ }^{5}$ these sites document the cultivation of a wide range of cereals, including the now extinct twograined einkorn and 'new-type' glume wheat. Pulses however are rare or absent, suggesting their cultivation was abandoned as farming spread east from the Fertile Crescent. A similar pattern has been observed at the southern end of the Iranian plateau, where the plant remains from seventh millennium B.C. Mehrgarh in modern-day Pakistan, evidence a dominance of cereal crops (mainly six-row barley) and absence of pulses. $^{6}$

The results outlined here represent the first comprehensive analysis of a Late Neolithic archaeobotanical assemblage in northwest Iran. Analysis of the charred macrobotanical assemblage from Khaleseh demonstrates that inhabitants were cultivating both cereals and pulses, with crops being processed and stored on-site. Samples collected during the excavation of a pottery kiln also indicate that wood

${ }^{3}$ Fazeli et al., 'The Neolithic to Chalcolithic Transition in the Qazvin Plain, Iran; Chronology and Subsistence Strategies'.

${ }^{4}$ Fuller, 'Charred Remains from Tappeh Sang-e Chakhmaq, and a Consideration of Early Wheat Diversity on the Eastern Margins of the Fertile Crescent'.

${ }^{5}$ Charles and Bogaard, 'Charred Plant Macro-Remains from Jeitun: Implications for Early Cultivation and Herding Practices in Western Central Asia'.

${ }^{6}$ Costantini, 'The Beginning of Agriculture in the Kachi Plain: The Evidence of Mehrgarh'; Costantini and Costantini-Biasini, 'Laboratory of Bioarchaeology'; Petrie, 'Mehrgarh, Pakistan'. 
charcoal, animal dung, the by-products of crop processing and wild mustard plants were all burned as fuel at the settlement. These findings are significant for our understanding of plant management and processes of Neolithisation in this currently understudied region. Moreover, they can contribute to ongoing debates regarding the chronology and routes of the eastward expansion of crops out of southwest Asia. ${ }^{7}$

Figure 1. Location of Tepe Khaleseh and other Late Neolithic sites mentioned in text with published archaeobotanical data.

\section{Location and archaeology of Tepe Khaleseh}

The archaeological site of Tepe Khaleseh $\left(36^{\circ} 11^{\prime} 22.0 \mathrm{~N}, 49^{\circ} 10^{\prime} 28.0 \mathrm{E}\right)$ lies on a fertile alluvial plain of the Abharrud Basin, approximately $300 \mathrm{~m}$ southwest of Khorram Dareh city in the Zanjan Province. An upland settlement, it is situated at an altitude of $1537 \mathrm{~m}$ asl. The site is less than 0.25 hectares in extent, with the archaeological mound reaching a height of $2 \mathrm{~m}$ above the surrounding landscape and $3 \mathrm{~m}$ of archaeological deposits evidenced in total (Fig. 2). Khaleseh was recorded during archaeological survey in $2003^{8}$ and in 2009 rescue excavations were carried out under the direction of Hamid

${ }^{7}$ Jones et al., 'The Trans-Eurasian Crop Exchange in Prehistory: Discerning Pathways from Barley Phylogeography'; Liu et al., 'Journey to the East: Diverse Routes and Variable Flowering Times for Wheat and Barley En Route to Prehistoric China'; Lister et al., 'Barley Heads East: Genetic Analyses Reveal Routes of Spread through Diverse Eurasian Landscapes'; Liu et al., 'The Virtues of Small Grain Size: Potential Pathways to a Distinguishing Feature of Asian Wheats'; Fuller, 'Agricultural Origins and Frontiers in South Asia: A Working Synthesis'.

${ }^{8}$ Aali, 'A Report on the First Season of the Archaeological Survey and Identification of Abharrud Basin (Abhhar and Khorram Darreh County)'; Aali, 'A Report on the Second 
Reza Valipour. ${ }^{9}$ Preliminary results from the 2009 field season indicate that Khaleseh represents a Late Neolithic single-period site dating to $c a$. $6000-5500 \mathrm{BC}$ based on the ceramic culture. Radiocarbon dating to establish a more precise date of occupation and a refined chronology of the site is currently underway.

Figure 2. View of Tepe Khaleseh looking southeast.

\section{Environment and vegetation}

The climate of the Zanjan province is cold and semi-arid. Mean monthly temperatures range from $0.6^{\circ} \mathrm{C}$ in January to $24.1^{\circ} \mathrm{C}$ in July and August. Due to the shielding-effect of the Alborz Mountains to the northeast, the province experiences only $322 \mathrm{~mm}$ of rainfall per year on average. This lies close to the limit for rainfed cultivation and today around $20 \%$ of wheat in the region is grown under irrigation. ${ }^{10}$ Precipitation occurs all year round, but mostly between October and May, with the highest levels recorded during the spring months and snow common in the winter. ${ }^{11}$ Today, agriculture is the principal occupation in the Zanjan Province. The main crops grown here are wheat, barley and alfalfa; the latter for forage. ${ }^{12}$ Cereal crops are typically sown in the winter

Season of the Archaeological Survey and Identification of Abharrud Basin (Abhar and Khorram Darreh County).'

${ }^{9}$ Valipour, 'Preliminary Report of Excavation at Tepe Khaleseh, Office of Cultural Heritage, Handicraft and Tourism of Zanjan Province.'; Valipour et al., 'Tepe Khaleseh, a Late Neolithic Site in Zanjan Province'.

${ }^{10}$ Ababaei and Etedali, 'Estimation of Water Footprint Components of Iran's Wheat Production: Comparison of Global and National Scale Estimates'.

${ }^{11}$ Alibaigi et al., 'Early Villages and Prehistoric Sites in the Abharroud Basi, Northwest of the Iranian Central Plateau'.

${ }^{12}$ Ghahremanzadeh et al., 'Designing a Whole-Farm Revenue Insurance for Agricultural Crops in Zanjan Province of Iran'. 
and harvested between May and August, with the rainfed crops maturing before the irrigated ones. ${ }^{13}$

The vegetation of the study area is classified as Irano-Turanian and is dominated by climax vegetation mostly in the form of steppe- or park-forests. ${ }^{14}$ Khaleseh lies at the intersection of several different phytogeographic sub-divisions, for example the Armeno-Iranian, Kurdo-Zagrossian and Central Iranian sectors ${ }^{15}$ meaning there is considerable variation in local vegetation. Furthermore, relatively small climatic changes in the past may have shifted the influence of these different phytogeographic zones significantly, although at present the fine-grained empirical evidence needed to reconstruct these sub-regional patterns is lacking. ${ }^{16}$ Today, the vegetation associated with Khaleseh is more steppic than that of the nearby Zagros Mountains, lacking its Mediterranean influence, and arboreal taxa rarely attain a tree-like form due to the harsh winters ${ }^{17}$ notable exceptions to this are pistachio trees. The Armeno-Iranian sector in this area is generally characterised by Juniper steppe-forest, while other steppic formations are dominated by Artemisia spp. ${ }^{18}$

\footnotetext{
${ }^{13}$ USDA-FAS, 'IRAN: 2008/09 Wheat Production Declines Due to Drought'.

${ }^{14}$ Zohary, Geobotanical Foundations of the Middle East. Two Volumes, 87.

${ }^{15}$ Bocherens et al., 'Palaeoenvironmental and Archaeological Implications of Isotopic Analyses $(13 \mathrm{C}, 15 \mathrm{~N})$ from Neolithic to Present in Qazvin Plain (Iran)'; Zohary, Geobotanical
} Foundations of the Middle East. Two Volumes, 194-99.

${ }^{16}$ Bocherens, Mashkour, and Billiou, 'Palaeoenvironmental and Archaeological Implications of Isotopic Analyses (13C, 15N) from Neolithic to Present in Qazvin Plain (Iran)'; Kehl, 'Quaternary Climate Change in Iran - the State of Knowledge'.

${ }^{17}$ Zohary, Geobotanical Foundations of the Middle East. Two Volumes, 196.

${ }^{18}$ Bobek, 'Vegetation', 283; Bocherens, Mashkour, and Billiou, 'Palaeoenvironmental and Archaeological Implications of Isotopic Analyses (13C, 15N) from Neolithic to Present in Qazvin Plain (Iran)'; Zohary, Geobotanical Foundations of the Middle East. Two Volumes, 194. 


\section{Archaeology}

Six trenches (I-VI) were opened up to explore Late Neolithic levels at Khaleseh in 2009 (Fig. 3) and three phases of occupation have been identified based on the cultural layers and architectural structures recorded. Phase I is represented by various clay and ash layers, whilst numerous architectural features were uncovered in Phases II and III, including mudbrick walls, flattened surfaces relating to floors and building collapse. Only Trench V records all three phases of occupation. Buildings at Khaleseh are rectilinear and follow a northwest-southeast orientation. Walls were constructed from mudbrick or pisé, with surfaces covered by a plaster of mud and straw. It is suggested that the roofs of buildings may have been flat and constructed from wooden poles and reeds that were covered with a mud-straw mixture. ${ }^{19}$

Figure 3. Topographic map of Tepe Khaleseh showing the location of Trenches I, II, III, IV, V and VI.

A range of heating surfaces, fireplaces and ovens attest to activities relating to cooking and craft at the site. Notable among these were the remains of a pottery kiln excavated in the eastern half of Trench V (see Fig. 4a, b). The kiln was located in an open space or courtyard near to areas of occupation and consisted of the remains of a short circular wall, associated ash layers, burnt floors and heated surfaces, as well as potsherds and wasters from pottery firing. ${ }^{20}$ When in use, vessels would have been placed within the short circular wall of the kiln and covered with a mud-straw plaster to create a closed firing environment. After firing the upper part of the plaster would have

\footnotetext{
${ }^{19}$ Valipour et al., 'Tepe Khaleseh, a Late Neolithic Site in Zanjan Province'.

${ }^{20}$ Valipour et al., 'Tepe Khaleseh, a Late Neolithic Site in Zanjan Province'.
} 
been destroyed to remove the fired pots and the process repeated each time the kiln was used. ${ }^{21}$ Evidence from the site suggests that in addition to closed kilns, ceramics were also fired in open spaces. ${ }^{22}$

Figure 4. (a) Plan of Trench V, showing architectural remains and pottery kiln, (b) image of pottery kiln with permanent lower short wall and traces of burning.

In addition to ceramics - the manufacture of which appears to have remained relatively consistent through the site's occupation - material culture at Khaleseh is represented by a rich lithic assemblage, clay objects and various stone tools; including grinding stones, pounding stones and pestles. The faunal assemblage is dominated by mammalian taxa, with sheep and goat accounting for $90 \%$ of all the identified faunal remains. ${ }^{23}$ Domestic cattle and domestic pig are also present. Small mammals include commensal rodents, while the bone and carapace of tortoise and a single bird bone have also been also recorded. ${ }^{24}$

\section{Methods}

Bulk soil samples were collected from all contexts (excluding topsoil) and processed by machine assisted water flotation. The bulk samples were typically processed as multiple smaller samples (2.75 litres on average) that were then amalgamated to avoid issues of duplication. ${ }^{25}$ Charred plant remains were collected in a mesh with an aperture of $c a$.

\footnotetext{
${ }^{21}$ Valipour et al., 'Tepe Khaleseh, a Late Neolithic Site in Zanjan Province'.

${ }^{22}$ Valipour et al., 'Tepe Khaleseh, a Late Neolithic Site in Zanjan Province'.

${ }^{23}$ Gręzak et al., 'Tepe Khaleseh (Iran), Season 2009'.

${ }^{24}$ Gręzak et al., 'Tepe Khaleseh (Iran), Season 2009'.

${ }^{25}$ Whitlam, 'Plant Use and Neolithic Societies of the Eastern Fertile Crescent, c.10,000-5500 BC', 93.
} 
$250 \mu \mathrm{m}$ and air-dried in the shade. Heavy residues (the non-floating fractions) were collected in an internal mesh with an aperture of $5 \mathrm{~mm}$, and any plant remains that had failed to float were removed by hand.

Samples were analysed at the Institute of Archaeology (University of Oxford) using a Leica model EZ4HD and CETI varizoom stereomicroscope at magnifications of 6x-40x. Due to time constraints, samples that were estimated to contain more than 500 plant remains were sub-sampled so that smaller fractions could be examined, following the principles laid out by van der Veen and Fieller. ${ }^{26}$ Identifications were made according to morphological characteristics, surface texture and size, and verified by comparison to modern reference material. The categorisation of wild grasses by grain size follows Whitlam et al. ${ }^{27}$ Plant remains were quantified using the principle of recording the 'minimum number of individuals' (MNI) following Jones ${ }^{28}$.

Wild plant taxa identified at the site have been further classified according to (1) their flowering/fruiting period in relation to the local harvest of rainfed cereals (May/June), (2) their likelihood of surviving animal digestion intact based on the hardness/thickness of their seed coat, whether they are enclosed and their size in relation to the reticulo-omasal orifice of the ruminant digestive system of sheep (1.18 $\mathrm{mm}^{29}$ ), and (3) according to their physical characteristics, which determine how they

${ }^{26}$ van der Veen and Fieller, 'Sampling Seeds'.

${ }^{27}$ Whitlam et al., 'Pre-Agricultural Plant Management in the Uplands of the Central Zagros: The Archaeobotanical Evidence from Sheikh-e Abad'.

${ }^{28}$ Jones, 'Numerical Analysis in Archaeobotany'.

${ }^{29}$ Poppi et al., 'The Relative Resistance to Escape of Leaf and Stem Particles from the Rumen of Cattle and Sheep'; Wallace and Charles, 'What Goes in Does Not Always Come out: The Impact of the Ruminant Digestive System of Sheep on Plant Material, and Its Importance for the Interpretation of Dung-Derived Archaeobotanical Assemblages'. 
behave during crop processing, ${ }^{30}$ for example their size, headedness (i.e. the tendency for seeds to stay in heads despite threshing) and aerodynamic properties (see Table 1). These classifications were used to explore the potential route(s) by which wild plants arrived on-site. Specifically, whether they were in seed at the time of harvest and arrived as arable crop weeds or whether they could have entered the archaeobotanical assemblage within animal dung that was burnt as a fuel. Information on seed characteristics and flowering/fruiting times was accumulated from the Flora of Iraq, ${ }^{31}$ the Kew seed database (http://data.kew.org/sid/) and other published studies. ${ }^{32}$

Table 1. Classification of weed types according to their physical characteristics and the stage of crop processing at which they are typically removed. Based on Table 5.15 in Hald $^{33}$.

Similarities and differences in the botanical composition of samples were also explored within correspondence analysis, a form of multivariate statistical analysis, which can be applied to search for patterns within the 'species-by-sample' datasets considered archaeobotanically. ${ }^{34}$ Prior to the analysis, taxonomic categories were amalgamated if

${ }^{30}$ Jones, 'A Statistical Approach to the Archaeological Identification of Crop Processing'; Jones, 'Interpretation of Archaeological Plant Remains: Ethnographic Models from Greece'.

${ }^{31}$ Townsend et al., Flora of Iraq, 2, 3, 4, 8, 9.

${ }^{32}$ Bogaard, Neolithic Farming in Central Europe: An Archaeobotanical Study of Crop Husbandry Practices; Charles and Bogaard, 'Charred Plant Macro-Remains from Jeitun: Implications for Early Cultivation and Herding Practices in Western Central Asia'; Hoppe, 'A Thousand Years of Farming: Agricultural Practices from The Byzantine to Early Ottoman Period at Khirbet Faris, The Kerak Plateau, Jordan'.

${ }^{33}$ Hald, A Thousand Years of Farming: Late Chalcolithic Agricultural Practices at Tell Brak in Northern Mesopotamia., 64.

${ }^{34}$ Jones, 'Numerical Analysis in Archaeobotany'; Lange, Plant Remains from a Native Settlement at the Roman Frontier: De Horden near Wijk Bij Duurstede. A Numerical Approach. 
they were likely to represent the same taxon and rare taxa were excluded (see Appendix table). This was done so that patterns identified during analysis reflect differences in botanical composition between samples and not differences in preservation that limited the level of identification. Correspondence analysis was carried out within the CANOCO for windows package and the results plotted using CANODRAW. ${ }^{35}$ Axis 1 was plotted horizontally and axis 2 vertically.

\section{Results}

A total of 27 samples from 26 contexts, excavated across trenches I, II, III, V and VI at Khaleseh, were analysed for this study. ${ }^{36}$ This corresponded to 223 litres of soil. ${ }^{37}$ The majority of samples came from Phase III, with only a handful of samples representing Phases I and II at the site. Four samples do not correspond to any phase. The 27 samples analysed produced an estimated 20,275 charred plant macroremains. ${ }^{38}$ The majority of these - over $85 \%$ - derive from Phase III deposits collected from in and around the pottery kiln in Trench V (samples 5013, 5015, 5016, 5026 and 5959). Thus, the major

\footnotetext{
${ }^{35}$ Smilauer, CANODRAW 3.0 User's Guide.; ter Braak and Smilauer, CANOCO for Windows Version 4.02.

${ }^{36}$ Originally 75 smaller samples, these were amalgamated, either prior to export, or after analysis based on similarities in their botanical composition and stratigraphical information. Each of the 26 contexts studied are therefore represented by single samples, except for C.5026 were differences in botanical composition meant two separate samples were recognised (S.5026 and S.5959).

${ }^{37}$ The samples reported on here represent the samples that were available to study at the time of this investigation. A further 78 samples from 30 contexts (230.75 litres of soil) remain to be studied.

${ }^{38}$ This figure represents the estimated number of plant remains across the assemblage after multiplying up all fractions to a $100 \%$ level to allow comparisons. The total number of plant remains before multiplication was 6558 .
} 
trends in the assemblage are spatial rather than chronological. Preservation of charred plant remains at the site is generally good, except when considering cereal grains, almost half of which (246 out of 504 items) could not be identified to species. Full compositional data for the 27 samples studied is presented in the appendix and summarised below in Table 2 .

Table 2. Summary of the frequency and abundance of major plant categories across the Khaleseh assemblage. Bold entries include total of all material (e.g. grain + chaff) including indeterminate categories. * includes cf. material

In addition to carpological remains, wood charcoal was a frequent component of samples (present in $88.9 \%$ of those analysed). Wood charcoal ranged in density from $0.0 \mathrm{ml}$ to $6.5 \mathrm{ml}$ per litre of soil, based on the volume of fragments larger than $2 \mathrm{~mm}$. Due to time limitations, this material could not be analysed further. Several nonbotanical remains were also recovered including rodent pellets. A total of 59 rodent pellets were found across 12 samples (44.4\%), suggesting that crops and/or their products were stored at the site (Fig. 5a). Charred animal dung, morphologically similar to modern sheep and goat dung, was also found in nine samples (33.3\%). This was represented by both fragmented remains and 12 intact pellets (Fig. 5b).

Figure 5. Important taxa/types at Khaleseh as discussed in text, (a) rodent pellets, (b) sheep/goat dung, (c) pulse stalk, (d) six-row naked barley rachis, identified by the welldeveloped outer florets and presence of residual glume material (M. Charles pers. comm.), (e) 'new-type' glume base, (f) Euclidium syriacum, (g) Goldbachia laevigata, (h) Aegilops grain, (i) Aegilops spikelets, (j) reed culm internodes, (k) Poaceae culm, basal.

\section{Crops}

Both cereal and pulse crops are present at Khaleseh, although pulses (found in $55.6 \%$ of 
samples) occur in relatively low numbers ${ }^{39}$ (Table 2). Pulses identified at the site include lentil (Lens sp.) and several Vicia/Lathyrus types that may have been cultivated. Moreover, the Vicia/Lathyrus types identified at Khaleseh do not correspond to taxa considered to be part of the 'founder crop package', ${ }^{40}$ namely bitter vetch (Vicia ervilia (L.) Willd.) and grass pea (Lathyrus sativus L.). Non-seed remains, in the form of fragments of potential legume stalk (Fig. 5c) and a single fragment of possible legume pod, were also recovered and provide tentative evidence for the processing of pulses onsite.

Within the cereals, barley (Hordeum vulgare L.) is the dominant crop type (found in $77.8 \%$ of samples). The majority of barley grain was either indeterminate in its identification or of the naked variety (H. vulgare var. nudum Hook. f.). Only two grains of hulled barley were found at the site (Table 2). Barley rachis was less abundant than barley grain (96 compared to 198 items) and nearly all rachis specimens (93 items) were found in two samples collected from the kiln in Trench V (samples 5026 and 5959). Both the six-row (Fig. 5d) and two-row forms of naked barley were identified as rachis remains; the latter from only a single specimen.

The other major group of cereals at Khaleseh are the glume wheats. These were found in nearly half the samples studied (44.4\%) and include both grain and chaff remains. In contrast to barley, amongst the glume wheats chaff is more abundant (58 glume bases compared to 27 grains). Glume wheats include one-grained einkorn

\footnotetext{
${ }^{39}$ It is important to note that pulses, along with other dense plant remains that are less likely to float, may be underrepresented at Khaleseh due to the large aperture of the internal mesh $(5 \mathrm{~mm})$.

${ }^{40}$ Zohary and Hopf, Domestication of Plants in the Old World: The Origin and Spread of Cultivated Plants in West Asia, Europe, and the Nile Valley. Third Edition.
} 
(Triticum monococcum L.), emmer (Triticum cf. dicoccum Schrank ex. Schübl.) and the 'new-type' glume wheat (Fig. 5e; Triticum 'new-type'), which was definitively identified from a single glume base on the basis of the morphology of its primary keel, which projects vertically and extends downwards to 'plug' into the attachment scar, and its secondary keel, which inserts into the rachis at an abrupt angle. ${ }^{41} \mathrm{~A}$ two-grained glume wheat that could not be identified to species due to fragmentation of the grains was also recovered. Specimens of this type were observed to have a flat-to-convex ventral face that is typical of two-grained glume wheats, and were also narrow in profile, suggesting they may represent the remains of two-grained einkorn rather than emmer wheat. However, this identification remains tentative given the limitations of identifying specific morphotypes from charred archaeobotanical remains, especially considering that a wider range of morphotypes, for which we lack modern counterparts, were probably cultivated in the past. ${ }^{42}$ Finally, free-threshing wheat (Triticum aestivum L./durum Desf.) was present in a handful of samples (11.1\%) and represented exclusively by grain.

Differences in the relative proportions of grain and chaff between these cereals, probably reflects the different ways in which they were processed for storage and consumption. The chaff of free-threshing cereals (i.e. barley and free-threshing wheat)

${ }^{41}$ Jones, Valamoti, and Charles, 'Early Crop Diversity: A "New” Glume Wheat from Northern Greece'.

${ }^{42}$ Miller, 'A Cautionary Note on the Use of Morphological Characters for Recognising Taxa in Wheat (Genus Triticum)'; Charles et al., "“Nor Ever Lightning Char Thy Grain”: Establishing Archaeologically Relevant Charring Conditions and Their Effect on Glume Wheat Grain Morphology'. 
is typically removed earlier in the crop processing sequence ${ }^{43}$ and therefore is less likely to be represented archaeobotanically, especially if the initial stages of crop processing take place off-site. In contrast the grains of glume wheats remain in their spikelets throughout the crop processing sequence and can be stored as spikelets before later dehusking. ${ }^{44}$

\section{Wild plants}

Dominating the assemblage in terms of abundance are the wild mustards (Brassicaceae), specifically Euclidium syriacum (L.) W. T. Aiton (Fig. 5f). ${ }^{45}$ This single taxon was found in $85.2 \%$ of samples and accounts for $c a .65 \%(13,151)$ of all the charred plant remains in the assemblage. Other wild mustards include Goldbachia laevigata DC. ${ }^{46}$

${ }^{43}$ Jones, 'The Application of Present-Day Cereal Processing Studies to Charred Archaeobotanical Remains'; Jones, 'Interpretation of Archaeological Plant Remains: Ethnographic Models from Greece'.

${ }^{44}$ Hillman, 'Reconstructing Crop Husbandry Practices from Charred Remains of Crops'; Hillman, 'Traditional Husbandry and Processing of Archaic Cereals in Modern Times: Part I, the Glume-Wheats'.

${ }^{45}$ The distinctive double-valved silique of E. syriacum was easily recognisable by the individual siliques that are joined by a thickened septum and have a beak-like apical projection. On either side of this septum the valves have a distinctive vein-like (rugose) surface pattern and each silique contains one seed. Although recorded as a monotypic genus in the Flora of Iraq, a second species of Euclidium (E. tenuissimum (Pall.) B. Fedtsch) has also been recorded in Iran and the identification of the Khaleseh specimens as E. syriacum is based on the morphological appearance of these fruits in comparison to modern reference material and the characteristic appearance of the beak which curves away from the pod, while in E. tenusissimum this is straight.

${ }^{46}$ Segmented pods of G. laevigata (M. Bieb) D.C. were frequently recovered, often still attached. Individual pod segments are barrel shaped with a strong vein running down each side for the length of the pod. They also possess a strongly reticulate surface pattern. The 
(Fig. 5g) and a double-podded mustard with small oval seeds (Brassicaceae type 1), which may correspond to a similar type described at Anau North by Miller. ${ }^{47}$ The majority of wild mustards were found in the external area of Trench V, from deposits in and around the pottery kiln. These samples also produced large quantities of wood charcoal and animal dung, suggesting that these materials were burnt together as fuel here.

Also frequent across the assemblage are medium-seeded wild grasses (found in 92.6\% of samples; see Table 3 for categorisation of wild grasses by grain size). Aegilops sp. (Fig. 5h, i) is particularly ubiquitous with the grain found in $66.7 \%$ of samples and the spikelets in $40.7 \%$ of samples. Other medium-seeded grasses include Taeniatherum caput-medusae (L.) Nevski (identified from both grain and rachis remains), Lolium sp., Eremopyrum sp. and Bromus spp. Two grains of the large-seeded wild barley (Hordeum spontaneum Koch) were also recorded (Table 2).

Table 3. Categorisation of wild grasses identified at Khaleseh by their grain size based on ellipsoid volume $\left(\mathrm{mm}^{3}\right)$ following Whitlam et al. (2018)

Other wild taxa that are frequent and/or abundant within the assemblage include potential arable weeds, for example small-seeded legumes, Adonis sp., Bellevalia sp., Galium spp., Papaver sp. and Artemisia sp. (Table 2). A few fragments of almond (Prunus amygdalus Batsch) nutshell were identified, and probably represent food remains, while fragments of charred amorphous matter (occurring in $44.4 \%$ of samples)

genus Goldbachia, which is not recorded in the Flora of Iraq, is listed as monotypic in the Flora of Turkey and Flora Iranica.

${ }^{47}$ Miller, 'The Use of Plants at Anau North'. 
potentially evidence the remains of food prepared for consumption. ${ }^{48}$ However, further analysis is required to substantiate this claim. Finally, cereal/grass (Poaceae) culm and reed culm were both present. These were variously represented by node, internode and basal material (Fig. 5j, k), which may reflect how they were 'collected' and brought to site (i.e. by cutting or uprooting). The potential routes by which wild taxa arrived onsite are considered in more detail below.

\section{Major sources of wild plant remains}

\section{Arable weeds and crop processing}

A weed origin is likely to account for the presence of the majority of wild plant remains within the assemblage. This inference is supported by the fact that nearly all the wild plant taxa identified at Khaleseh are classified as being early-to-intermediate in their seasonality (Table 4). This means they would have been in seed at the time of harvest and could plausibly have arrived on-site with the crop. An exception to this is Artemisia, which is classified as intermediate-to-late in its seasonality, meaning it is unlikely to have been in seed when the harvest took place and another explanation is required to account for its presence in the assemblage.

\footnotetext{
${ }^{48}$ Fuller and Gonzalez Carretero, 'The Archaeology of Neolithic Cooking Traditions: Archaeobotanical Approaches to Baking, Boiling and Fermenting.'; Arranz-Otaegui et al., 'Archaeobotanical Evidence Reveals the Origins of Bread 14,400 Years Ago in Northeastern Jordan'; González Carretero, Wollstonecroft, and Fuller, ‘A Methodological Approach to the Study of Archaeological Cereal Meals: A Case Study at Çatalhöyük East (Turkey)'.
} 
Table 4. Wild plant taxa at Khaleseh and their classification according to seasonality, physical properties relating to crop processing (see Table 1 for details) and likelihood of surviving ruminant digestion intact, as described in the methods.

Crop-weed relationships have been explored further in correspondence analysis. An analysis was conducted on all taxa and types that occur in at least three samples (38 taxa) ${ }^{49}$ and samples containing at least 10 items of these taxa and types ( 25 samples). ${ }^{50}$ Rodent pellets were included as an additional variable to see how they related to botanical taxa, after first checking that their inclusion did not unduly influence the analysis. Figure 6 presents the species plot for the analysis coded according to categories of plant remain, with wild plant taxa further classified by physical attributes relating to crop processing (Table 4 , see also Table 1 ).

Figure 6. Correspondence analysis of 38 taxa based on their occurrence in 25 samples. Taxa coded according to major categories with wild taxa further classified by physical attributes that relate to crop processing (see Table 1 for details).

Figure 6 demonstrates a clear separation between crop products (cereal grain and pulse seeds), which pull out to the right of the plot along axis 1 (horizontal), and crop by-products, such as glume bases and barley rachis that group closer to the origin (centre) of axis 1, and along axis 2 (vertical). Associated with crop products to the right of the plot are several wild plant taxa identified as arable weeds, for example Adonis,

\footnotetext{
${ }^{49}$ Prior to data analysis, taxa and type categories were amalgamated where appropriate so that patterns identified in the analysis reflected differences in botanical composition rather than limitations of preservation or identification (see Appendix).

${ }^{50}$ Except for S.3010, which behaved as an outlier in a series of test analyses and was therefore removed.
} 
Bellevalia, Lolium, Eremopyrum and Aegilops grain. Their association with crop products in the analysis reflects the fact that these 'big, free and heavy' (BFH) seeds (Table 4), would only have been removed during the final stage(s) of the crop processing sequence. It should also be noted, that whilst Aegilops grain occupies this position in the analysis, Aegilops spikelets are located near to the centre of the plot where they are associated with glume bases, mirroring the separation between glume wheat grain and chaff. Aegilops is a well-documented glume wheat 'mimic'51 and the pattern observed here is consistent with the interpretation of Aegilops as a crop mimic that was dehusked alongside glume wheats. Also, grouping near to the centre of the plot and showing a strong affinity with glume bases and Aegilops spikelets are rodent pellets. This suggests that these remains derive from the refuse of storage deposits, adding further weight to the inference that glume wheats were stored as spikelets at the site, prior to the final stages of processing and dehusking.

Finally, also associated with crop by-products towards the centre of the plot and along axis 2 , are a range of wild taxa which display varied physical characteristics in relation to their behaviour during crop processing and which, therefore, are unlikely to derive from a single stage of the crop processing sequence.

It should be noted that the majority of samples at Khaleseh contain a mixture of barley and glume wheats. As these crops are unlikely to be grown and processed alongside each other due to their different processing sequences, ${ }^{52}$ this mixing must have taken place after crop processing. Therefore, the weed seeds within samples are likely to derive from more than one source, limiting their potential for further crop

\footnotetext{
${ }^{51}$ Barrett, 'Crop Mimicry in Weeds'.

52 Jones and Halstead, 'Maslins, Mixtures and Monocrops: On the Interpretation of Archaeobotanical Crop Samples of Heterogeneaous Composition'.
} 
processing and ecological analyses. However, based on the physical properties of the wild taxa identified in the assemblage - which relate to how these behave during the crop processing sequence (Table 4 , see also Table 1) - we can tentatively infer that all stages of the crop processing sequence were taking place at, or near to, the site. The presence of barley rachis and cereal/grass culm in samples, provides further evidence that the early stages of crop processing took place in close proximity to the settlement. This may have been favourable to provide a source of temper for building materials and pottery manufacture.

\section{Animal dung as a source of plant remains}

The identification of sheep/goat dung at Khaleseh raises the possibility that some plant remains may have entered the assemblage within animal dung burnt as a fuel. Unambiguous evidence for taxa having a dung origin can only be provided by the identification of plant material within charred dung pellets. ${ }^{53}$ Three of the 12 intact dung pellets from Khaleseh were dissected to see if any plant material could be identified within their matrix, but none was observed. However, animal dung cannot be excluded as a source of charred plant remains, especially when considering taxa that have a high likelihood of surviving ruminant digestion intact (see Table 4). Artemisia is one such taxon and its inclusion in animal dung that was subsequently burned provides a plausible route by which seeds of this taxon may have arrived on-site and entered the archaeobotanical assemblage (a weed origin having been previously been excluded

\footnotetext{
${ }^{53}$ Charles, 'Fodder from Dung: The Recognition and Interpretation of Dung-Derived Plant Material from Archaeological Sites'; Miller and Smart, 'Intentional Burning of Dung as Fuel: A Mechanism for the Incorporation of Charred Seeds into the Archaeological Record'.
} 
above).

Other wild plants classified as having a high likelihood of surviving animal digestion intact, include the weedy taxa Galium, Papaver, Fumaria, Lamiaceae and Vaccaria pyramidata Medik. Along with Artemisia, these small-seeded taxa group together at the bottom left of the correspondence analysis plot shown in Figure 6 . In the corresponding sample plot for this analysis (Fig. 7), the majority of samples which occupy this position relate to external areas and/or fire installations at the site (Fig. 7a). These samples also produced the largest volumes of charred animal dung (Fig. 7b). In contrast, samples to the right of the plot, which correspond to crop products and weeds from the latter stages of crop processing, were collected from internal areas and contained little to no animal dung.

Figure 7. Correspondence analysis plot of 25 samples on the basis of 38 taxa, with samples coded according to (a) internal/external space and origin within fireinstallations, and (b) volume of dung ( $\mathrm{ml}$ ) found in samples.

The association of small-seeded taxa that have a high probability of surviving animal digestion intact, with samples from external areas and fire installations at the site, which are rich in charred animal dung, suggests these taxa may have a dung origin. However, while we do not exclude a dung origin for any wild taxa at the site especially for those ranked as having a high likelihood of surviving in dung - as the majority of wild taxa identified at Khaleseh would have been in seed at the time of harvest these can more reasonably be interpreted as crop weeds (Artemisia being the notable exception). The presence of numerous small-seeded taxa within samples that also contain animal dung, and which derive from external deposits and fire installations, can alternatively be explained by the disposal of crop processing by-products as a casual 
fuel. ${ }^{54}$ It should also be noted that these two routes into the assemblage are not mutually exclusive. Numerous ethnographic studies cite husbandry practices where the byproducts of crop processing are fed to animals,${ }^{55}$ meaning they could arrive on-site as crop weeds but have entered the assemblage indirectly through the burning of animal dung. It is also plausible that some animal dung, along with culm and chaff, was used to temper pottery and/or the mudbrick of the kiln itself, as documented both ethnographically and archaeologically. ${ }^{56}$

\section{Wild mustards - a gathered fuel?}

The final group of wild taxa to consider in terms of their origin and taphonomy are the wild mustards, which are dominated by a single species - Euclidium syriacum. While it is possible that these arrived on-site with the harvest based on their seasonality (Table 4), we exclude this route based on their abundance in relation to crop remains. It is also unlikely that these mustards are dung derived, given their relatively large size and low likelihood of surviving animal digestion intact (see Table 4). Supporting this inference is the observation that many specimens were recovered as intact siliques, often with woody stem attachments, which would be unlikely if they had been subject to ruminant digestion. This also suggests they were not being processed and cleaned as a food and/or a source of oil; as has been suggested for wild mustard taxa at other Neolithic

\footnotetext{
${ }^{54}$ van der Veen, 'Formation Processes of Desiccated and Carbonized Plant Remains - the Identification of Routine Practice'.

${ }^{55}$ Barnard and Kristoferson, 'Agricultural Residues as Fuel in the Third World'; Anderson and Ertuğ-Yaras, 'Fuel Fodder and Faeces: An Ethnographic and Botanical Study of Dung Fuel Use in Central Anatolia'.

${ }^{56}$ van der Veen, 'Formation Processes of Desiccated and Carbonized Plant Remains - the Identification of Routine Practice'; van der Veen, 'The Economic Value of Chaff and Straw in Arid and Temperate Zones'.
} 
sites, for example Çatalhöyük, in central Anatolia ${ }^{57}$ and the Late Neolithic sites of Aratashen and Aknashen in Armenia. ${ }^{58}$

The most plausible explanation for the presence of wild mustards at Khaleseh is that they were burned as a fuel. This hypothesis is supported by the large concentrations of wild mustards found in samples from fire installations at the site - the majority from deposits in and around the pottery kiln in Trench V. Figure 8 presents the plan of Trench V with samples that contained ten or more items plotted according to their location and represented by pie-charts illustrating botanical composition. ${ }^{59}$ A clear split is illustrated between internal and external spaces. Samples from internal areas, located in the western half of Trench V (samples 5017, 5022, 5045), are dominated by crop remains. These produced no rodent pellets, culm or animal dung and only small amounts of wood charcoal. In contrast, samples to the east of the trench, relating to the pottery kiln (samples 5013, 5015, 5016, 5026 and 5959), are dominated by wild mustards and also produced large quantities of wood charcoal, culm and rodent pellets; the latter from the disposal of storage refuse as a casual fuel here. Furthermore, samples 5026 and 5959, which were collected from inside the kiln itself, produced ten of the 12 intact dung pellets found at the site. The remaining two pellets being recovered from ashy layers in Trench II (sample 2017). This strong contextual association between the kiln, other fuel remnants and wild mustards, suggests the latter were almost certainly

\footnotetext{
${ }^{57}$ Bogaard et al., 'The Archaeobotany of Mid-Later Neolithic Occupation Levels at Çatalhöyük'.

${ }^{58}$ Hovsepyan and Willcox, 'The Earliest Finds of Cultivated Plants in Armenia: Evidence from Charred Remains and Crop Processing Residues in Pise from the Neolithic Settlements of Aratashen and Aknashen'.

${ }^{59}$ For the purposes of this analysis samples have been included regardless of phasing to maximise sample inclusion, although he majority are from Phase III (see Table 2).
} 
burnt as a fuel within this feature. The fact that many mustards are preserved as intact siliques with woody stem attachments, indicates that these were collected as whole plants, rather than just the fruits. As small (10-40 cm tall) highly branched plants,${ }^{60}$ taxa such as Euclidium syriacum would have been easy to collect and been a convenient source of fuel.

Figure 8. Plan of Trench V showing location of samples that contain ten or more items of plant remains (from all phases) within internal and external spaces. Samples depicted as pie charts illustrating botanical composition based on major categories of plant remain. Number of rodent pellets, animal dung pellets and density of wood charcoal $(>2$ $\mathrm{mm}$ ) found within each sample are illustrated by labelled circles.

\section{Discussion}

The archaeobotanical samples analysed for this study have provided significant insights into plant management at Khaleseh, especially food production and fuel use. A consistent set of crops is attested across all three phases of occupation, dominated by barley; primarily six-row naked barley although the two-row naked form may also have been cultivated based on the identification a single rachis internode. Two grains of hulled barley indicate that it was present at the site but based on this limited representation it is difficult to establish whether this was intentionally cultivated or represents a crop contaminant. There is also evidence for the cultivation of one-grained einkorn, emmer and free-threshing wheat, as well as the now extinct 'new-type' glume wheat and potentially also two-grained einkorn. Thus, at least five and possibly up to seven cereal crops were cultivated at the site. This range of cereal crops is in agreement

\footnotetext{
${ }^{60}$ Townsend et al., Flora of Iraq, 2, 3, 4, 8, 9.
} 
with findings from Sang-e Chakmaq, ${ }^{61}$ Chahar Boneh ${ }^{62}$ and Jeitun ${ }^{63}$ and points towards a continuum in the cultivation of cereal crops across the north Iranian corridor during the Late Neolithic. In contrast to cereals, pulse crops are relatively rare at Khaleseh. They include lentil, as well as potentially cultivated Vicia/Lathyrus types. Although limited in number, the recovery of pulses here is significant given their absence at contemporary sites in the region, and their presence at Khaleseh extends the range of pulse cultivation during the Late Neolithic into northern Iran for the first time. It is interesting to note that, while pulses are also absent at Neolithic Mehrgarh, toward the southern end of the Iranian plateau, ${ }^{64}$ lentil and Vicia types have been recorded from Neolithic sites in the Caucasus, for example, Aratashen and Aknashen in Armenia, which both date to the sixth millennium B.C. ${ }^{65}$ Taken together with evidence for pulse cultivation at Khaleseh, this suggests northwest Iran represents one route by which these crops spread into northern Eurasia during the Neolithic. In contrast, it is not until the Bronze Age - and possibly as the result of later episodes of crop dispersal - that we see

${ }^{61}$ Fuller, 'Charred Remains from Tappeh Sang-e Chakhmaq, and a Consideration of Early Wheat Diversity on the Eastern Margins of the Fertile Crescent'.

${ }^{62}$ Fazeli et al., 'The Neolithic to Chalcolithic Transition in the Qazvin Plain, Iran; Chronology and Subsistence Strategies'.

${ }^{63}$ Charles and Bogaard, 'Charred Plant Macro-Remains from Jeitun: Implications for Early Cultivation and Herding Practices in Western Central Asia'.

${ }^{64}$ Costantini, 'The Beginning of Agriculture in the Kachi Plain: The Evidence of Mehrgarh'; Costantini and Costantini-Biasini, 'Laboratory of Bioarchaeology'; Petrie, 'Mehrgarh, Pakistan'.

${ }^{65}$ Hovsepyan and Willcox, 'The Earliest Finds of Cultivated Plants in Armenia: Evidence from Charred Remains and Crop Processing Residues in Pise from the Neolithic Settlements of Aratashen and Aknashen'. 
widespread evidence for pulse cultivation in northern Iran and central Asia, including at Tepe Hissar (Iran), Djarktun (Uzebekistan), Gonur and Anau South (Turkmenistan). ${ }^{66}$ Pulses being absent from earlier fifth millennium B.C. occupation at Anau North. These findings require further evaluation within the context of current models for transEurasian crop exchange, which indicates this took place across several different routes and over multiple episodes in prehistory, as crops that had evolved in southwest Asia were adopted and adapted to new environments and socio-cultural spheres. ${ }^{67}$

The analyses undertaken for this study have also demonstrated that a range of agricultural activities took place at the site, including the processing of cereals for storage and consumption. All stages of the crop processing sequence are suggested to have taken place at, or near to, the settlement. A more refined assessment is currently prevented by the low numbers of crop items within individual samples, as well as their mixed crop composition that rules out identification of specific crop-weed relationships. The storage of crops is evidenced by the presence of rodent pellets and their association with crop by-products, especially glume bases, which were stored in their spikelets prior

${ }^{66}$ Costantini and Dyson, 'The Ancient Agriculture of the Damghan Plain: The Archaeobotanical Evidence from Tepe Hissar'; Miller, 'The Use of Plants at Anau North'; Miller, 'Preliminary Archaeobotanical Results from the 1989 Excavation at the Central Asian Site of Gonur Depe, Turkmenistan'; Miller, 'Agricultural Development in Western Central Asia in the Chalcolithic and Bronze Ages'.

${ }^{67}$ Lister et al., 'Barley Heads East: Genetic Analyses Reveal Routes of Spread through Diverse Eurasian Landscapes'; Fuller, 'Agricultural Origins and Frontiers in South Asia: A Working Synthesis'; Liu et al., 'Journey to the East: Diverse Routes and Variable Flowering Times for Wheat and Barley En Route to Prehistoric China'; Jones et al., 'The Trans-Eurasian Crop Exchange in Prehistory: Discerning Pathways from Barley Phylogeography’. 
to dehusking. There is also tentative evidence for the processing of pulses at Khaleseh based on the presence of legume pod and stalk material, which suggests these may have been brought to site and stored in their pods before being de-shelled for cooking and consumption.

Wild plant foods at Khaleseh are less well-represented, and the only taxa interpreted as having a dietary role at the site is almond. It is plausible that other wild taxa identified at the site were consumed, although these are more reasonably interpreted as arriving on-site by other means, for example as arable weeds. However, it should be noted that charred plant assemblages significantly underrepresent wild plant foods ${ }^{68}$ and the plant diet at Khaleseh was almost certainly broader than we can reasonably infer from the evidence currently available.

Finally, a significant discovery made during this study concerns the range of plants and other materials that were burned as fuel at Khaleseh. Specifically, for firing pottery, as evidenced by the charred plant remains recovered from the kiln in Trench V. Fuel remains identified at the site include wood charcoal, wild mustards, animal dung and the by-products of crop processing. This mixed fuel assemblage is consistent with ethnographic observations of pottery firing, which record the use of straw, dung cakes, vine cuttings, desert brush, grasses, weeds, reeds and charcoal as fuels. ${ }^{69}$

${ }^{68}$ Colledge and Conolly, 'Wild Plant Use in European Neolithic Subsistence Economies'.

${ }^{69}$ Matson, “"Ceramic Ecology”: An Approach to the Study of Early Cultures of the Near East.', 210; Sillar, 'Dung by Preference: The Choice of Fuel as an Example of How Andean Pottery Production Is Embedded within Wider Technical, Social and Economic Practices'; Smith, 'Bonfire II: The Return of Pottery Firing Temperatures'; Wood, The Sociology of Pottery in Ancient Palestine: The Ceramic Industry and the Diffusion of Ceramic Style in the Bronze and Iron Age., 93. 
It is difficult based on available evidence, to evaluate to what extent this mixed assemblage represents the wider fuel economy at Khaleseh; or whether different fuels were selected for specific properties. Animal dung for example, is known to be a stable, slow burning fuel that burns without producing vigorous flames and is highly suited to cooking and pottery firing, as widely attested both ethnographically and archaeologically.$^{70}$ In contrast, little is reported about the functionality or role of wild mustards as a fuel. Ethnographic reports of the dried stalks of mustard plants being used as a primary fuel source in glass-making, observe that these produced large flames when burnt ${ }^{71}$ and in later prehistory mustard oil was often used as an illuminant. ${ }^{72}$ The high levels of preservation of plant remains recovered from the kiln suggest that they were charred at temperatures close to the optimal charring window $\left(220-240^{\circ} \mathrm{C}\right)$, or at higher temperatures $\left(350-400^{\circ} \mathrm{C}\right)$ within a reduced oxygen environment. ${ }^{73}$ These temperature ranges are slightly below minimum firing temperatures for pottery $(500-$ $700^{\circ} \mathrm{C}$ ) and well below those typically reached within a closed firing environment,

${ }^{70}$ Charles, 'Fodder from Dung: The Recognition and Interpretation of Dung-Derived Plant Material from Archaeological Sites'; Lancelotti, “"Not All That Burns Is Wood”. A Social Perspective on Fuel Exploitation and Use during the Indus Urban Period (2600-1900 BC)'; Portillo et al., 'An Ethnoarchaeological Study of Livestock Dung Fuels from Cooking Installations in Northern Tunisia'; Sillar, 'Dung by Preference: The Choice of Fuel as an Example of How Andean Pottery Production Is Embedded within Wider Technical, Social and Economic Practices'; Spengler, 'Dung Burning in the Archaeobotanical Record of West Asia: Where Are We Now?'

${ }^{71}$ Sode and Kock, 'Traditional Raw Glass Production in Northern India: The Final Stage of an Ancient Technology.', 162.

${ }^{72}$ Colombini et al., 'Organic Mass Spectrometry in Archaeology: Evidence for Brassicaceae Seed Oil in Egyptian Ceramic Lamps'.

${ }^{73}$ Charles et al., "“Nor Ever Lightning Char Thy Grain”: Establishing Archaeologically Relevant Charring Conditions and Their Effect on Glume Wheat Grain Morphology'. 
which can be upwards of $1000^{\circ} \mathrm{C} .{ }^{74} \mathrm{We}$ may, therefore, be dealing with fuel remains that were added at a specific stage of the firing process, that occupied an area of the kiln where temperatures and oxygen levels were lower, or that were burnt within this feature for a purpose other than firing pottery (e.g. cooking).

Ultimately, fuel use at the site was probably dependent on a number of factors relating to the availability of different materials, the temperature, duration, size and function of the fire, as well as cultural preferences. Additional analyses will be needed to shed more light onto this aspect of the plant economy at the site.

\section{Conclusion}

The archaeobotanical data presented here provide an important record for an underrepresented region for the Late Neolithic period. A diverse crop spectrum is evidenced at Khaleseh that is consistent with comparable assemblages from northern Iran, but which notably includes pulses that have yet to be definitively identified at other sites in the region. This indicates that the spread of a farming out of the eastern Fertile Crescent and into northwest Iran was based on a mixed 'package' of cereal and pulse crops, although the latter may have been abandoned as farming spread eastwards through the north Iranian mountain corridor.

Analyses undertaken for this study have also demonstrated that a range of plantbased activities took place at Khaleseh, relating to the processing, storage and consumption of crops, as well as the selection of fuel for pottery firing and/or other activities. Further investigations will be needed to corroborate these findings and

\footnotetext{
${ }^{74}$ Rye, Pottery Technology: Principles and Reconstruction; Smith, 'Bonfire II: The Return of Pottery Firing Temperatures'.
} 
evaluate their significance with respect to current models for the spread of farming and development of specialised industries during the Late Neolithic.

\section{Bibliography}

Aali, A. 'A Report on the First Season of the Archaeological Survey and Identification of Abharrud Basin (Abhhar and Khorram Darreh County)'. Unpublished report in Archive of Cultural Heritage Organization of Zanjan Province. (in Persian), 2004.

Aali, A. 'A Report on the Second Season of the Archaeological Survey and Identification of Abharrud Basin (Abhar and Khorram Darreh County).' Unpublished report in Archive of Cultural Heritage Organization of Zanjan Province. (in Persian), 2006.

Ababaei, Behnam, and Hadi Ramezani Etedali. 'Estimation of Water Footprint Components of Iran's Wheat Production: Comparison of Global and National Scale Estimates'. Environmental Processes 1, no. 3 (1 September 2014): 193205. https://doi.org/10.1007/s40710-014-0017-7.

Alibaigi, Sajjad, Shokouh Khosravi, and Abolfazl Aali. 'Early Villages and Prehistoric Sites in the Abharroud Basi, Northwest of the Iranian Central Plateau'. Documenta Praehistorica XXXIX (2012): 459-72. https://doi.org/10.4312/dp.39.34.

Anderson, S., and F. Ertuğ-Yaras. 'Fuel Fodder and Faeces: An Ethnographic and Botanical Study of Dung Fuel Use in Central Anatolia'. Environmental Archaeology 1 (1998): 99-109.

Arranz-Otaegui, A., L. Gonzalez Carretero, M. Ramsey, D. Q. Fuller, and T. Richter. 'Archaeobotanical Evidence Reveals the Origins of Bread 14,400 Years Ago in Northeastern Jordan'. Proceedings of the National Academy of Sciences 115, no. 31 (31 July 2018): 7925. https://doi.org/10.1073/pnas.1801071115

Barnard, G., and L. Kristoferson. 'Agricultural Residues as Fuel in the Third World', 1985.

Barrett, S. C. H. 'Crop Mimicry in Weeds'. Economic Botany 37 (1983): 255-82.

Bobek, H. 'Vegetation'. In Cambridge History of Iran, edited by W-G Fisher, 1:280293, 1968. 
Bocherens, Hervé, Marjan Mashkour, and Daniel Billiou. 'Palaeoenvironmental and Archaeological Implications of Isotopic Analyses (13C, 15N) from Neolithic to Present in Qazvin Plain (Iran)'. Environmental Archaeology 5, no. 1 (1 June 2000): 1-19. https://doi.org/10.1179/env.2000.5.1.1.

Bogaard, A., M. Charles, A. Livarda, M. Ergun, D. Filipovic, and G. Jones. 'The Archaeobotany of Mid-Later Neolithic Occupation Levels at Çatalhöyük'. In Humans and Landscapes of Çatalhöyük: Hodder (Ed.), 93-128. Reports from the 2000-2008 Seasons. Los Angeles: Monographs of the Cotsen Institute of Archaeology, University of California at Los Angeles, 2013.

Bogaard, A. Neolithic Farming in Central Europe: An Archaeobotanical Study of Crop Husbandry Practices. Routledge, 2004.

Braak, C. F. J. ter., and P. Smilauer. CANOCO for Windows Version 4.02. Wageningen: Centre for Biometry, 1997.

Charles, M. 'Fodder from Dung: The Recognition and Interpretation of Dung-Derived Plant Material from Archaeological Sites'. Environmental Archaeology: The Journal of Human Palaeoecology 1 (1998): 111-22.

Charles, M., and A. Bogaard. 'Charred Plant Macro-Remains from Jeitun: Implications for Early Cultivation and Herding Practices in Western Central Asia'. In Origins of Agriculture in Western Central Asia, 150-65, 2010.

Charles, M., E. Forster, M. Wallace, and G. Jones. "“Nor Ever Lightning Char Thy Grain": Establishing Archaeologically Relevant Charring Conditions and Their Effect on Glume Wheat Grain Morphology'. STAR: Science \& Technology of Archaeological Research 1, no. 1 (31 March 2015): 1-6. https://doi.org/10.1179/2054892315Y.0000000008.

Colledge, S., and J. Conolly. 'Wild Plant Use in European Neolithic Subsistence Economies: A Formal Assessment of Preservation Bias in Archaeobotanical Assemblages and the Implications for Understanding Changes in Plant Diet Breadth'. Quaternary Science Reviews 101 (1 October 2014): 193-206. https://doi.org/10.1016/j.quascirev.2014.07.013.

Colombini, M. P., F. Modugno, and E. Ribechini. 'Organic Mass Spectrometry in Archaeology: Evidence for Brassicaceae Seed Oil in Egyptian Ceramic Lamps'. Journal of Mass Spectrometry 40, no. 7 (2 June 2005): 890-98. https://doi.org/10.1002/jms.865. 
Costantini, L. 'The Beginning of Agriculture in the Kachi Plain: The Evidence of Mehrgarh'. In South Asian Archaeology 1981, edited by Bridget Allchin, 29-33. Cambridge: Cambrdige University Press, 1983.

Costantini, L., and L. Costantini-Biasini. 'Laboratory of Bioarchaeology'. East and West 35 (1985): 331-336.

Costantini, L., and R. H. Dyson. 'The Ancient Agriculture of the Damghan Plain: The Archaeobotanical Evidence from Tepe Hissar'. In Economy and Settlement in the Near East. Analyses of Ancient Sites and Materials, edited by Naomi F. Miller, Vol. Supplement to volume 7. MASCA Research Papers in Science and Archaeology. Philadelphia, PA: MASCA, University Museum, 1990.

Fazeli, H., A. Beshkani, A. Markosian, H. Ilkhani, S.R. Abbasnegad, and R. Young. 'The Neolithic to Chalcolithic Transition in the Qazvin Plain, Iran; Chronology and Subsistence Strategies'. Archäologische Mitteilungen Aus Iran Und Turan 41 (2009): 1-21.

http://archive.org/details/NeolithicToChalcolithicTransitionInTheQazvinPlain20 09.

Fuller, D. Q. 'Agricultural Origins and Frontiers in South Asia: A Working Synthesis'. Journal of World Prehistory 20 (2006): 1-86

Fuller, D. Q. 'Charred Remains from Tappeh Sang-e Chakhmaq, and a Consideration of Early Wheat Diversity on the Eastern Margins of the Fertile Crescent'. In The First Farming Village in Northeast Iran and Turan: Tappeh Sang-e Chakhmaq and Beyond, 33-36. Research Center for West Asian Civilization, University of Tsukuba, 2014.

Fuller, D. Q., and L. Gonzalez Carretero. 'The Archaeology of Neolithic Cooking Traditions: Archaeobotanical Approaches to Baking, Boiling and Fermenting.' Archaeology International 21 (2018): 109-121.

Ghahremanzadeh, M., R. Mohammadrezaei, G. Dashti, and M. Ainollahi. 'Designing a Whole-Farm Revenue Insurance for Agricultural Crops in Zanjan Province of Iran'. Economía Agraria y Recursos Naturales 17, no. 2 (2017): 29-53.

González Carretero, L., M. Wollstonecroft, and D. Q. Fuller. 'A Methodological Approach to the Study of Archaeological Cereal Meals: A Case Study at Çatalhöyük East (Turkey)'. Vegetation History and Archaeobotany 26, no. 4 (1 July 2017): 415-32. https://doi.org/10.1007/s00334-017-0602-6. 
Gręzak, A., A Soltysiak, Hamid Reza Valipour, and Hossein Davoudi. 'Tepe Khaleseh (Iran), Season 2009'. Bioarchaeology of the Near East 4 (2010): 58-62.

Hald, M. M. A Thousand Years of Farming: Late Chalcolithic Agricultural Practices at Tell Brak in Northern Mesopotamia. 1880. Oxford: Archaeopress: B.A.R. International Series, 2008.

Hillman, G. 'Traditional Husbandry and Processing of Archaic Cereals in Modern Times: Part I, the Glume-Wheats'. Bulletin on Sumerian Agriculture 1 (1984): $114-52$.

Hillman, G. 'Reconstructing Crop Husbandry Practices from Charred Remains of Crops'. In Farming Practice in British Prehistory, edited by R.J. Mercer, 12362. Edinburgh: Edinburgh University Press, 1981.

Hoppe, C. 'A Thousand Years of Farming: Agricultural Practices from The Byzantine to Early Ottoman Period at Khirbet Faris, The Kerak Plateau, Jordan'. Ph.D, University of Sheffield, 2001.

Hovsepyan, R., and G. Willcox. 'The Earliest Finds of Cultivated Plants in Armenia: Evidence from Charred Remains and Crop Processing Residues in Pise from the Neolithic Settlements of Aratashen and Aknashen'. Vegetation History and Archaeobotany 17 (December 2008): S63-71. ://000262846100009.

Jones, G. 'Numerical Analysis in Archaeobotany'. In Progress in Old World Palaeoethnobotany, edited by Willem van Zeist, Krystyna Wasylikowa, and Karl-Ernst Behre, 63-80. Rotterdam: A.A. Balkema, 1991.

Jones, G. 'The Application of Present-Day Cereal Processing Studies to Charred Archaeobotanical Remains'. Circea 6 (1990): 91-96.

Jones, G. 'A Statistical Approach to the Archaeological Identification of Crop Processing'. Journal of Archaeological Science 14, no. 3 (May 1987): 311-23. https://doi.org/10.1016/0305-4403(87)90019-7.

Jones, G. 'Interpretation of Archaeological Plant Remains: Ethnographic Models from Greece'. In Plants and Ancient Man: Studies in Palaeoethnobotany, edited by W. van Zeist and W. A. Casparie, 43-61. Rotterdam: Balkema, 1984.

Jones, G., and P. Halstead. 'Maslins, Mixtures and Monocrops: On the Interpretation of Archaeobotanical Crop Samples of Heterogeneaous Composition'. Journal of Archaeological Science 22 (1995): 103-14. 
Jones, G., S. Valamoti, and M. Charles. 'Early Crop Diversity: A “New” Glume Wheat from Northern Greece'. Vegetation History and Archaeobotany 9 (October 2000): 133-46.

Jones, Huw, Diane L. Lister, Dawei Cai, Catherine J. Kneale, James Cockram, Leonor Peña-Chocarro, and Martin K. Jones. 'The Trans-Eurasian Crop Exchange in Prehistory: Discerning Pathways from Barley Phylogeography'. Domestication East Asia 426 (28 December 2016): 26-32.

https://doi.org/10.1016/j.quaint.2016.02.029.

Karamidehkordi, E., and A. Hashemi. 'Farmers' Knowledge of Integrated Pest Management: A Case Study in the Zanjan Province in Iran'. ISDA. Montpellier, France: Cirad-INRA-SupAgro, 2010.

Kehl, Martin. 'Quaternary Climate Change in Iran — the State of Knowledge'. Erdkunde, 2009, 1-17.

Kohler-Schneider, M. 'Contents of a Storage Pit from Late Bronze Age Stillfried, Austria: Another Record of the "New" Glume Wheat'. Vegetation History and Archaeobotany 12 (2003): 105-11.

Lancelotti, C. "Not All That Burns Is Wood". A Social Perspective on Fuel Exploitation and Use during the Indus Urban Period (2600-1900 BC)'. PLOS ONE 13, no. 3 (7 March 2018): e0192364. https://doi.org/10.1371/journal.pone.0192364.

Lange, A. G. Plant Remains from a Native Settlement at the Roman Frontier: De Horden near Wijk Bij Duurstede. A Numerical Approach. Amersfoort: Nederlandse Oudheden, 1990.

Lister, Diane L., Huw Jones, Hugo R. Oliveira, Cameron A. Petrie, Xinyi Liu, James Cockram, Catherine J. Kneale, Olga Kovaleva, and Martin K. Jones. 'Barley Heads East: Genetic Analyses Reveal Routes of Spread through Diverse Eurasian Landscapes'. PLOS ONE 13, no. 7 (18 July 2018): e0196652. https://doi.org/10.1371/journal.pone.0196652.

Liu, Xinyi, Diane L. Lister, Zhijun Zhao, Cameron A. Petrie, Xiongsheng Zeng, Penelope J. Jones, Richard A. Staff, et al. 'Journey to the East: Diverse Routes and Variable Flowering Times for Wheat and Barley En Route to Prehistoric China'. PLOS ONE 12, no. 11 (2 November 2017): e0187405. https://doi.org/10.1371/journal.pone.0187405. 
Liu, Xinyi, Diane L. Lister, Zhijun Zhao, Richard A. Staff, Penelope J. Jones, Liping Zhou, Anil K. Pokharia, et al. 'The Virtues of Small Grain Size: Potential Pathways to a Distinguishing Feature of Asian Wheats'. Domestication East Asia 426 (28 December 2016): 107-19. https://doi.org/10.1016/j.quaint.2016.02.059.

Matson, F. R. "“Ceramic Ecology": An Approach to the Study of Early Cultures of the Near East.' In Ceramics and Man, edited by F.R. Matson, 202-217. 41. New York: Wenner-Gren Foundation for Anthropological Research: Viking Fund Publications in Anthropology, 1965.

Miller, N. F. 'Preliminary Archaeobotanical Results from the 1989 Excavation at the Central Asian Site of Gonur Depe, Turkmenistan'. International Association for the Study of the Cultures of Central Asia. Information Bulletin 19 (1993): 14963.

Miller, N. F. 'Agricultural Development in Western Central Asia in the Chalcolithic and Bronze Ages'. Vegetation History and Archaeobotany 8 (1999): 13-19.

Miller, N. F. 'The Use of Plants at Anau North'. In A Central Asian Village at the Dawn of Civilization, Excavations at Anau, Turkmenistan, Fredrik T. Hiebert., 127-38. University Museum Monograph 116. Philadelphia: University of Pennsylvannia Museum of Archaeology and Anthropology, 2003.

Miller, N. F., and T. L. Smart. 'Intentional Burning of Dung as Fuel: A Mechanism for the Incorporation of Charred Seeds into the Archaeological Record'. Journal of Ethnobiology 4 (1984): 15-28.

Miller, T. E. 'A Cautionary Note on the Use of Morphological Characters for Recognising Taxa in Wheat (Genus Triticum)'. In Préhistoire de l'agriculture: Nouvelles Approches Expérimentales et Ethnographiques, edited by Patricia C Anderson, 6:249-53. Monographie Du Centre de Recherches Archéologiques. Paris: Éditions du CNRS, 1992.

Petrie, Cameron A. 'Mehrgarh, Pakistan'. In The Cambridge World History Volume IIA World with Agriculture, 12,000 BCE-500 CE., edited by G. Barker and C. Goucher, 289-309. Cambridge: Cambrdige University Press, 2015.

Poppi, D. P., R. E. Hendricksen, and D. J. Minson. 'The Relative Resistance to Escape of Leaf and Stem Particles from the Rumen of Cattle and Sheep'. Journal of Agricultural Science, no. 18 (1985): 9-14. 
Portillo, M., M. Carme Belarte, Joan Ramon, Nabil Kallala, Joan Sanmartí, and Rosa M. Albert. 'An Ethnoarchaeological Study of Livestock Dung Fuels from Cooking Installations in Northern Tunisia'. An Archaeology of Fuels: Social and Environmental Factors in Behavioural Strategies of Multi-Resource Management 431 (28 February 2017): 131-44. https://doi.org/10.1016/j.quaint.2015.12.040.

Sillar, B. 'Dung by Preference: The Choice of Fuel as an Example of How Andean Pottery Production Is Embedded within Wider Technical, Social and Economic Practices'. Archaeometry 42 (1998).

Smilauer, P. CANODRAW 3.0 User's Guide. New York: Microcomputer Power, 1992.

Smith, A. 'Bonfire II: The Return of Pottery Firing Temperatures'. Journal of Archaeological Science 28 (2001): 991-1003.

Sode, T., and J. Kock. 'Traditional Raw Glass Production in Northern India: The Final Stage of an Ancient Technology.' Journal of Glass Studies 43 (2001): 155-169. Spengler, R.N. 'Dung Burning in the Archaeobotanical Record of West Asia: Where Are We Now?' Vegetation History and Archaeobotany, 31 January 2018. https://doi.org/10.1007/s00334-018-0669-8.

Townsend, C. C., E. R. Guest, and A. al-Rawi. Flora of Iraq, 2, 3, 4, 8, 9. Baghdad: Ministry of Agriculture and Agrarian Reform, 1966.

USDA-FAS. 'IRAN: 2008/09 Wheat Production Declines Due to Drought'. Commodity Intelligence Report, 2008. https://ipad.fas.usda.gov/highlights/2008/05/Iran_may2008.htm.

Valipour, H. R. 'Preliminary report of excavation at Tepe Khaleseh, Office of Cultural Heritage, Handicraft and Tourism of Zanjan Province. Unpublished Report, (2009).

Valipour, H. R., H. Davoudi, J. Hoseinzadeh, and H. Fazeli. 'Tepe Khaleseh: Archaeological Evaluation of a Late Neolithic Site in North-Western Iran'. Antiquity Project Gallery, no. 331 (2012).

Valipour, H. R., H. Davoudi, I. Mostafapour, and A. Gręzak. 'Tepe Khaleseh, a Late Neolithic Site in Zanjan Province'. In The Neolithisation of Iran: The Formation of New Societies, Edited by R. Matthews and H.Fazeli Nashli., 3:147-77. Themes from the Ancient Near East BANEA Publication Series. Oxford and Oakville: Oxbow Books, 2013. 
van der Veen, M. 'Formation Processes of Desiccated and Carbonized Plant Remains the Identification of Routine Practice'. Journal of Archaeological Science 34, no. 6 (June 2007): 968-90. https://doi.org/10.1016/j.jas.2006.09.007.

van der Veen, M. 'The Economic Value of Chaff and Straw in Arid and Temperate Zones'. Vegetation History and Archaeobotany 8 (1999): 211-24.

van der Veen, M., and Nick Fieller. 'Sampling Seeds'. Journal of Archaeological Science 9 (1982): 287-98.

Wallace, M., and M, Charles. 'What Goes in Does Not Always Come out: The Impact of the Ruminant Digestive System of Sheep on Plant Material, and Its Importance for the Interpretation of Dung-Derived Archaeobotanical Assemblages'. Journal of Environmental Archaeology 18, no. 1 (2013): 18-30. https://doi.org/0.1179/1461410313Z.00000000022.

Whitlam, J. 'Plant Use and Neolithic Societies of the Eastern Fertile Crescent, c.10,000-5500 BC'. Ph.D, University of Reading, UK, 2015.

Whitlam, J., A. Bogaard, R. Matthews, W. Matthews, Y. Mohammadifar, H. Ilkhani, and M. Charles. 'Pre-Agricultural Plant Management in the Uplands of the Central Zagros: The Archaeobotanical Evidence from Sheikh-e Abad'. Vegetation History and Archaeobotany, 15 March 2018. https://doi.org/10.1007/s00334-018-0675-x.

Wood, B. G. The Sociology of Pottery in Ancient Palestine: The Ceramic Industry and the Diffusion of Ceramic Style in the Bronze and Iron Age. Sheffield Academic Press, 1990.

Zohary, D., and M. Hopf. Domestication of Plants in the Old World: The Origin and Spread of Cultivated Plants in West Asia, Europe, and the Nile Valley. Third Edition. Oxford: Clarendon Press, 2000.

Zohary, Daniel, Maria Hopf, and Ehud Weiss. Domestication of Plants in the Old World: The Origin and Spread of Domesticated Plants in Southwest Asia, Europe, and the Mediterranean Basin. Fourth Edition. 2013.

Zohary, M. Geobotanical Foundations of the Middle East. Two Volumes. Stuttgart: Gustav Fischer, 1973. 